\title{
Trajectories of health care service utilization and differences in patient characteristics among adults with specific chronic pain: analysis of health plan member claims
}

\author{
This article was published in the following Dove Press journal: \\ Journal of Pain Research \\ 20 February 2013 \\ Number of times this article has been viewed
}

\author{
Charles Ruetsch' \\ Joseph Tkacz' \\ Peter G Kardel' \\ Andrew Howe ${ }^{2}$ \\ Helen $\mathrm{Pai}^{2}$ \\ Bennett Levitan ${ }^{3}$ \\ 'Health Analytics, LLC, Columbia, \\ Maryland, ${ }^{2}$ Janssen Research \& \\ Development, Raritan, New Jersey, \\ ${ }^{3}$ Janssen Research \& Development, \\ Titusville, New Jersey, USA
}

\begin{abstract}
Introduction: The lack of consistency surrounding the diagnosis of chronic non-cancer pain, treatment approaches, and patient management suggests the need for further research to better characterize the chronic non-cancer pain population.

Objective: The purpose of this study was to identify distinct trajectories of health care service utilization of chronic non-cancer pain patients and describe the characteristic differences between trajectory groups.
\end{abstract}

Patients and methods: This study utilized the MarketScan claims databases. A total of 71,392 patients diagnosed with either low back pain or osteoarthritis between 2006 and 2009 served as the study sample. Each subject's claims data were divided into three time periods around an initial diagnosis date: pre-period, post-Year 1, and post-Year 2. Subjects were categorized as either high $(\mathrm{H})$ or low $(\mathrm{L})$ cost at each post period, resulting in the creation of four trajectory groups based on the post-Year 1 and 2 cost pattern: H-H, H-L, L-H, and L-L. Multivariate statistical tests were used to predict and discriminate between trajectory group memberships.

Results: The H-H, L-H, and H-L groups each utilized significantly greater pre-period highcost venue services, post-Year 1 outpatient services, and post-Year 1 opioids compared to the L-L group $(P<0.001)$. Additionally, the $\mathrm{H}-\mathrm{H}$ and $\mathrm{L}-\mathrm{H}$ groups displayed elevated Charlson comorbidity index scores compared with the L-L group $(P<0.001)$, with each showing increased odds of having both opioid dependence and cardiovascular disease diagnoses $(P<0.01)$.

Conclusion: This study identified patient characteristics among chronic pain patients that discriminated between different levels of post-index high-cost venue service utilization and trajectories of change in the same. With implications for managed care program implementation and resource management, this study highlights results from a developed algorithm that employed a variety of accessible data elements to effectively discriminate between patients based on their pattern of high-cost venue service utilization over time.

Keywords: opioids, pharmacoeconomics, addiction, health care, claims analysis

\section{Introduction}

"Chronic pain," defined by the International Association for the Study of Pain, is any pain that persists beyond the expected healing phase following an injury, is any pain that persists beyond the expected healing phase or longer than three months. ${ }^{1}$ However, alternative definitions have been used when pain persists for more than 6 months. ${ }^{2}$ The lack of consistency surrounding the diagnosis of chronic non-cancer pain (CNCP), treatment
Correspondence: Joseph Tkacz 9200 Rumsey Road, Columbia, MD 21045 , USA

Tel + I 4109973314

Fax + I 4109974545

Email joseph.tkacz@healthanalytic.com 
approaches, and patient management suggests the need for further research on better characterizing the CNCP population.

CNCP is often associated with primary diagnoses such as low back pain (LBP), osteoarthritis (OA), fibromyalgia, and diabetic neuropathy. ${ }^{3-5}$ CNCP patients have numerous nonpharmacologic treatment options available to them, including exercise, psychological and behavioral interventions, and a variety of non-traditional treatment approaches including acupuncture, vitamins and herbal preparations. ${ }^{6}$ However, the most common form of treatment for CNCP is opioid analgesic medication. These medications, while highly effective at relieving pain, are associated with elevated risk for addiction, opioid-induced adverse events, decrement in level of functioning, and increased use of high-cost venue health care services. ${ }^{5,7,8}$ On average, for those diagnosed with CNCP, pain tends to persist for a median of 10 years (range 3-50 years), and while pain persists, so does opioid therapy, facilitating the emergence of secondary disorders. Furthermore, in opposition to the World Health Organization's analgesic ladder, ${ }^{9}$ the most commonly prescribed opioid analgesic is oxycodone, indicated for moderate to severe pain (representing 53\% of all opioid use). ${ }^{4,10}$

Compared with their non-pain counterparts, patients experiencing CNCP also tend to use more health care services, resulting in an increase in health care spending. ${ }^{11,12}$ With estimates of up to $26 \%$ of the population reporting persistent pain during the prior 6 months, ${ }^{13}$ research on drivers, service utilization, provider practice patterns, and treatment outcomes are of increasing importance to payers. Previous research has focused on the sequelae of LBP in relation to patient recovery or symptomatology at various time points $(3,6$, or 12 months $)$ but studies of longer duration are less common within the literature and may be of value to payers. ${ }^{13}$

Payers are becoming more aware of the costs associated with opioid analgesia overuse and the emergence of addiction ${ }^{15}$ as well as the potential benefit of effective interventions to patients as well as their employer clients. To address the increased health care service utilization and associated costs as well as the personal suffering associated with CNCP, many health plans and other payers have made management of these patients a priority. ${ }^{16}$ Given the high prevalence of pain-related conditions, the efficient and effective delivery of these programs requires tools to identify pain patients at greatest risk for utilizing high-cost venue services, based on pre-morbid predictors and other process variables. Therefore, the aim of the present study was to identify and describe patient groups by their changes in or stability of health care expenditure as a proxy of their pain intensity. Specifically, the two main study objectives were: (1) to develop a method of defining distinct patient groups based on health care expenditure patterns and (2) to determine the characteristics associated with membership in these groups.

\section{Methods}

\section{Sample selection}

A random sample $(25 \%)$ of patients with a diagnosis of LBP or OA was extracted from the MarketScan database $(\mathrm{N}=4.4 \mathrm{M})$ of aggregated redacted commercial claims during calendar years 2006 through 2009. The following inclusion and exclusion criteria were imposed on all subjects:

- at minimum, three International Classification of Diseases, Ninth Revision, Clinical Modification diagnoses of either LBP or OA spanning $\geq 180$ days during the 18-month case-finding window (subjects evidencing both diagnoses were excluded)

- continuous eligibility for the 30-month measurement period

- six-month pre-event pain-naive period

- at least 18 years of age

- absence of cancer, schizophrenia, traumatic brain injury, and mental retardation diagnoses during the study period.

For all subjects, three study-period windows were created:

1. pre-period: the six-month pre-pain diagnosis period

2. post-Year 1: the first 12-month post-pain diagnosis follow-up period

3. post-Year 2: the second 12-month post-pain diagnosis follow-up period.

\section{Statistical analyses}

The statistical analysis involved four steps.

\section{Demographic, service utilization and costs by diagnosis group}

Demographic information, including baseline comorbidities, was calculated for each diagnosis group. Additionally, during each of the three primary study periods, service utilization and cost estimates were calculated for each group. Claims reversals were removed before any cost estimates were made.

\section{Development of health care utilization and costs latent factors}

Second, latent variables that represented service utilization and health care expenditure were used to model patient 
health-related behavior during the pre- and each of the two post-periods. The goal was to produce a simple dimensional scale that represented service and pharmacy utilization and cost of care based on summarized administrative claims for service and pharmacy. The manifest variables were inpatient admissions, emergency room (ER) visits, the summed total of inpatient and ER costs, physician/clinic visits, laboratory days, prescription fills, and total outpatient costs. A two-factor solution adequately represented the data based on eigenvalues $>1.0$ and scree plot analysis. The two factors showed consistency across measurement periods, with the manifest indicators loading in the same order providing for adequate metric invariance. ${ }^{17}$ The pattern of manifest indicator loadings into the two factors may be summarized as:

- Factor 1: high-cost venue service use intensity (HCVSUI)

- Factor 2: outpatient service use intensity (OPSUI)

Factor scores for both HCVSUI and OPSUI for the preperiod as well as for both post-index periods were stored for each case, as these values were used in the clustering and final model.

\section{Clustering cases on latent factor scores and creation of trajectory groups}

K-means clustering of case-level HCVSUI factor scores at post-Year 1 and post-Year 2 separated cases into high and low HCVSUI factor scores at both periods. Trajectory groups were then based on change in group membership from post-Year 1 to 2 . Finally, once cases were separated into trajectory groups, group membership was predicted using multivariate analyses. Descriptive statistics included group comparisons on demographic and comorbidity profiles, in addition to service utilization and cost estimates during the follow-up periods.

\section{Predicting trajectory groups}

Identifying predictors of trajectory group membership was the final step of these analyses. Therefore, given that trajectory group was a polytomous categorical variable, a multinomial regression model was used. Multinomial regression analysis predicted group trajectory membership using pre-period service utilization, comorbid diagnoses, pharmacy utilization, and postYear 1 OPSUI scores. Demographic information (eg, age, sex, employment status), primary diagnosis (eg, diabetes, specific back injury), comorbid diagnoses (ie, individual diagnoses as well as the Charlson comorbidity index), and service utilization during the pre- and post-periods (ie, the 6 months prior to and
2 years subsequent to the appearance of a pain diagnosis) were regressed onto trajectory groups.

\section{Results Analyses by diagnosis group}

The final study sample, after applying inclusion and exclusion criteria, included 71,392 patients with $\operatorname{LBP}(\mathrm{N}=37,991)$ or OA $(\mathrm{N}=33,401)$. Table 1 highlights descriptive demographic statistics for the sample. Overall, the sample was predominantly female $(59.1 \%)$, aged $47.7 \pm 9.27$ years old, and residing in the southern (49.6\%) and north central (29.3\%) regions of the USA. The mean Charlson comorbidity index (a measure of overall illness) of the sample was $0.22 \pm 0.55$, with nearly a quarter of the sample having a history of both cardiovascular disease (22.4\%) and psychotropic prescription fills (22.3\%). Table 2 presents estimates of service utilization and cost measures annualized across the 2-year follow-up measurement period. An average of 0.15 per person per year inpatient hospital admissions, totaling US\$2728 annually, was incurred by this sample. Similarly, the sample used an average of 0.41 ER visits totaling US\$229 each. The sample used an average of 7.72 visits to physician offices at an annual cost of US $\$ 590$, and filled 19 prescriptions (for any prescription medication) at an annual cost of US\$1534. The average annual per patient health care cost incurred by this sample during the two-year post-period was US\$10,412.

\section{Latent factor analysis}

Principal component factor analyses of service utilization and cost manifest indicators at pre-period, post-Year 1 and post-Year 2 returned a two-principal component solution (calculated separately for each year) based on eigenvalue $>1.00$ and scree plot. Loadings $\geq 0.40$ were considered significant. Upon rotation, the two factors were (1) HCVSUI, representing the manifest variables of inpatient admissions, ER visits, and the summed total of inpatient and ER costs; and (2) OPSUI, representing the manifest variables of physician/ clinic visits, laboratory days, prescription fills, and total outpatient costs. Figures 1 and 2 show the final factor diagrams with standardized estimates.

\section{Clustering analysis}

The K-mean cluster procedure was chosen to assign cases to service utilization intensity groups because it is the most robust for working with large samples. For the HCVSUI factors, both two and three cluster solutions adequately represented the data, but for parsimony and ease of interpretation, the two-cluster solution was adopted. At each time period 
Table I Study sample descriptive statistics by pain group

\begin{tabular}{|c|c|c|c|c|c|c|}
\hline \multirow[t]{2}{*}{ Variable } & \multicolumn{2}{|c|}{ LBP group $(\mathbf{N}=37,991)$} & \multicolumn{2}{|c|}{ OA group $(N=33,40 I)$} & \multicolumn{2}{|c|}{ Total $(\mathbf{N}=71,392)$} \\
\hline & Mean/f & (SD)/\% & Mean/f & (SD)/\% & Mean/f & $(\mathbf{S D}) / \%$ \\
\hline Male & 16,109 & $42.4 \%$ & 12,500 & $37.4 \%$ & 28,609 & $40.1 \%$ \\
\hline Age & 46.00 & 9.73 & 49.57 & 8.32 & 47.67 & 9.27 \\
\hline Northeast region & 2525 & $6.6 \%$ & 2296 & $6.9 \%$ & 4821 & $6.8 \%$ \\
\hline North central region & II,533 & $30.4 \%$ & 9357 & $28.0 \%$ & 20,890 & $29.3 \%$ \\
\hline South region & 18,342 & $48.3 \%$ & $|7,09|$ & $51.2 \%$ & 35,433 & $49.6 \%$ \\
\hline West region & 5454 & $14.4 \%$ & 4518 & $13.5 \%$ & 9972 & $14.0 \%$ \\
\hline Unknown region & 137 & $0.4 \%$ & 139 & $0.4 \%$ & 276 & $0.4 \%$ \\
\hline Charlson comorbidity index & 0.19 & 0.52 & 0.24 & 0.58 & 0.22 & 0.55 \\
\hline \multicolumn{7}{|l|}{ Related comorbidities } \\
\hline Depression & 1105 & $2.9 \%$ & 1010 & $3.0 \%$ & 2115 & $3.0 \%$ \\
\hline Anxiety & 1179 & $3.1 \%$ & 793 & $2.4 \%$ & 1972 & $2.8 \%$ \\
\hline Opioid dependence & 486 & $1.3 \%$ & 283 & $0.8 \%$ & 769 & $1.1 \%$ \\
\hline Bipolar disorder & 219 & $0.6 \%$ & 154 & $0.5 \%$ & 373 & $0.5 \%$ \\
\hline Sleep disturbance/insomnia & 1782 & $4.7 \%$ & 1647 & $4.9 \%$ & 3429 & $4.8 \%$ \\
\hline Sickle cell disease & 6 & $0.0 \%$ & 8 & $0.0 \%$ & 14 & $0.0 \%$ \\
\hline Fibromyalgia & $|35|$ & $3.6 \%$ & 999 & $3.0 \%$ & 2350 & $3.3 \%$ \\
\hline Cardiovascular disease & 7398 & $19.5 \%$ & 8610 & $25.8 \%$ & 16,008 & $22.4 \%$ \\
\hline Migraine/chronic headache & 1098 & $2.9 \%$ & 734 & $2.2 \%$ & 1832 & $2.6 \%$ \\
\hline Post-traumatic stress disorder & 94 & $0.2 \%$ & 69 & $0.2 \%$ & 163 & $0.2 \%$ \\
\hline \multicolumn{7}{|l|}{ Related covariates } \\
\hline Mental health visits $(\mathrm{N})$ & 2664 & $7.0 \%$ & 2240 & $6.7 \%$ & 4904 & $6.9 \%$ \\
\hline Psychotropic Rx fills (N) & 8519 & $22.4 \%$ & 7431 & $22.2 \%$ & 15,950 & $22.3 \%$ \\
\hline
\end{tabular}

Note: Data are derived from the pre-period.

Abbreviations: LBP, low back pain; OA, osteoarthritis; Rx, prescription; SD, standard deviation.

(pre, post-Year 1 and 2), cases were clustered into two groups that mapped onto "high" and "low" levels of HCVSUI factor scores.

\section{Trajectory groups analyses}

Once clustered, patients were further grouped based on change in group status from post-Year 1 to post-Year 2. Change in cluster membership over time was calculated to designate valence of HCVSUI trajectory and four specific trajectory groups were identified:

1. High to High: post-Year 1 high HCVSUI to post-Year 2 high HCVSUI

2. Low to High: post-Year 1 low HCVSUI to post-Year 2 high HCVSUI

3. High to Low: post-Year 1 high HCVSUI to post-Year 2 low HCVSUI

4. Low to Low: post-Year 1 low HCVSUI to post-Year 2 low HCVSUI.

Tables 3-5 present the univariate statistics for patient characteristics, service utilization, and costs by HCVSUI trajectory group. Patients who remained in the high HCVSUI category through both post-periods comprised the smallest group ( $\mathrm{N}=469 ; 0.66 \%)$ but also accounted for the highest overall per member per year (PMPY) health care spend at US\$69,032 and US\$80,148 for post-Year 1 and 2 , respectively $(P<0.001)$. Further, the High to High group had the highest prevalence of all measured baseline comorbid conditions. The group that changed from Low to High was the next smallest ( $\mathrm{N}=1612 ; 2.26 \%$ ), with their PMPY total health care costs more than quadrupling from US\$15,366 in post-Year 1 to US\$68,787 in post-Year 2. Conversely, the High to Low group ( $\mathrm{N}=2553 ; 3.58 \%)$ reduced their total PMPY health care spend substantially from US\$61,664 in post-Year 1 to US\$13,891 in post-Year 2. Finally, the Low to Low group comprised the majority of the sample $(\mathrm{N}=66,758 ; 93.51 \%)$ and spent the least overall PMPY, US\$8,579 and US\$7,503, during post-Year 1 and 2, respectively. Figures 3 and 4 show graphical representations of select cost data.

Table 6 presents the final trimmed multinomial model. Based on the full set of a priori predictors and covariates, neither the goodness-of-fit statistic $(P<0.01)$, nor the omnibus test (pseudo $\mathrm{R}^{2}=0.028$ ) was acceptable. The model was trimmed of specific predictors and covariates based on two criteria: (1) those that did not adequately predict the criterion variable and (2) those that were not imperative to the theoretical model. A second model, based on a subset of the predictors and covariates used in the original model resolved and reached acceptable levels of both goodness of fit $(P=1.0)$ and the omnibus test (pseudo $\mathrm{R}^{2}=0.169$ ). 
Table 2 Post-index service utilization and cost* of care by pain group

\begin{tabular}{|c|c|c|c|c|c|c|}
\hline \multirow[t]{2}{*}{ Variable } & \multicolumn{2}{|c|}{ LBP group $(\mathrm{N}=37,991)$} & \multicolumn{2}{|c|}{ OA group $(N=33,40 I)$} & \multicolumn{2}{|c|}{ Total $(\mathbf{N}=71,392)$} \\
\hline & Mean/f & (SD)/\% & Mean/f & (SD)/\% & Mean/f & $(\mathbf{S D}) / \%$ \\
\hline \multicolumn{7}{|l|}{ High-cost venue manifest variables } \\
\hline Number of inpatient hospital admissions & 0.13 & 0.38 & 0.17 & 0.4 & 0.15 & 0.39 \\
\hline Number of people with $\geq$ I hospital admission & 7125 & $18.75 \%$ & 7588 & $22.72 \%$ & $14,7 \mid 3$ & $20.61 \%$ \\
\hline Number of inpatient hospital days & 0.48 & 2.3 & 0.63 & 2.42 & 0.55 & 2.36 \\
\hline Total inpatient hospital costs & $\$ 2471.28$ & $\$ 9972.41$ & $\$ 3019.45$ & $\$ 9658.93$ & $\$ 2727.74$ & $\$ 9830.73$ \\
\hline Number of emergency room visits & 0.41 & 1.18 & 0.4 & 1.12 & 0.41 & 1.15 \\
\hline $\begin{array}{l}\text { Number of people with } \geq \text { I emergency } \\
\text { room visits }\end{array}$ & $|3,90|$ & $36.59 \%$ & 12,278 & $36.76 \%$ & 26,179 & $36.67 \%$ \\
\hline Range of emergency room visits & $0-81.5$ & & $0-64.5$ & & $0-81.5$ & \\
\hline Total emergency room costs & $\$ 236.97$ & $\$ 1,022.58$ & $\$ 220.17$ & $\$ 730.48$ & $\$ 229.11$ & $\$ 897.86$ \\
\hline \multicolumn{7}{|l|}{ Outpatient health service manifest variables } \\
\hline Number of physician and clinic visits & 7.37 & 5.67 & 8.12 & 5.13 & 7.72 & 5.43 \\
\hline Total physician and clinic costs & $\$ 565.30$ & $\$ 480.27$ & $\$ 617.44$ & $\$ 503.43$ & $\$ 589.69$ & $\$ 491.92$ \\
\hline Total outpatient costs & $\$ 5789.19$ & $\$ 8104.21$ & $\$ 6562.13$ & $\$ 8824.32$ & $\$ 6150.81$ & $\$ 8457.49$ \\
\hline Number of Rx fills & 18.50 & 24.95 & 19.43 & 24.44 & 18.93 & 24.72 \\
\hline Total $R \times$ costs & $\$ 1509.53$ & $\$ 3399.83$ & $\$ 1562.26$ & $\$ 3377.07$ & $\$ 1534.20$ & $\$ 3389.28$ \\
\hline \multicolumn{7}{|l|}{ Total cost variables } \\
\hline High-cost venue services (IP + ER) & $\$ 2708.25$ & $\$ 10,189.15$ & $\$ 3239.61$ & $\$ 9839.08$ & $\$ 2956.85$ & $\$ 10,030.33$ \\
\hline Total medical costs (IP + OP) & $\$ 8260.46$ & $\$ 14,230.66$ & $\$ 9581.57$ & $\$ 14,823.00$ & $\$ 8878.55$ & $\$ 14,525.66$ \\
\hline Total health care costs (IP $+O P+R x)$ & $\$ 9,770.00$ & $\$ 15,242.80$ & $\$ 11,143.84$ & $\$ 15,697.22$ & $\$ 10,412.75$ & $\$ 15,482.15$ \\
\hline
\end{tabular}

Notes: *All monetary values shown are in US dollars. Data presented are annualized estimates over the entire measurement period.

Abbreviations: ER, emergency room; IP, inpatient; LBP, low back pain; OA, osteoarthritis; OP, outpatient; Rx, prescription; SD, standard deviation.

\section{Pre-period}

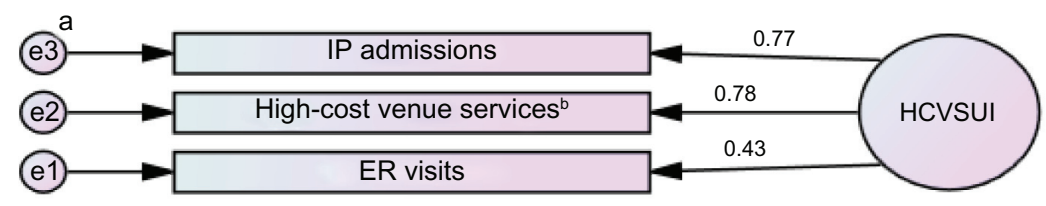

Post-Year 1

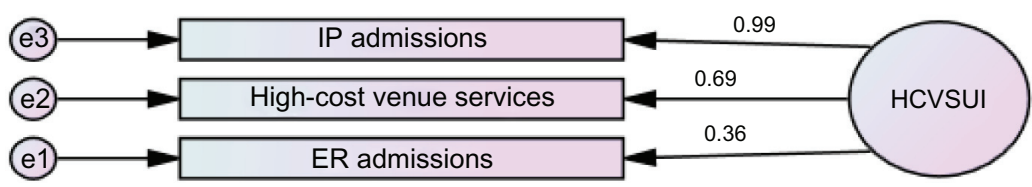

\section{Post-Year 2}

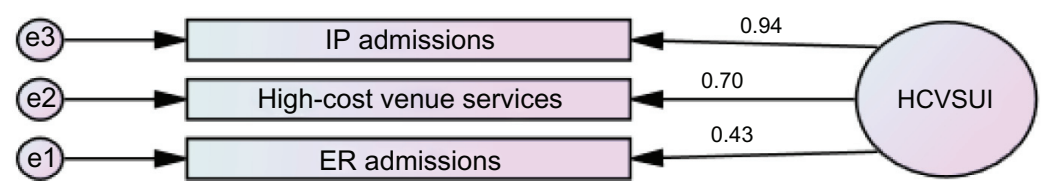

Figure I Factor analysis results: high-cost venue service utilization intensity (HCVSUI).

Notes: ${ }^{a}$ Error; ${ }^{b}$ the high-cost venue services variable is the summed amount of ER and inpatient costs.

Abbreviations: ER, emergency room; HCVSUI, high cost venue service utilization intensity; IP, inpatient. 


\section{Pre-period}

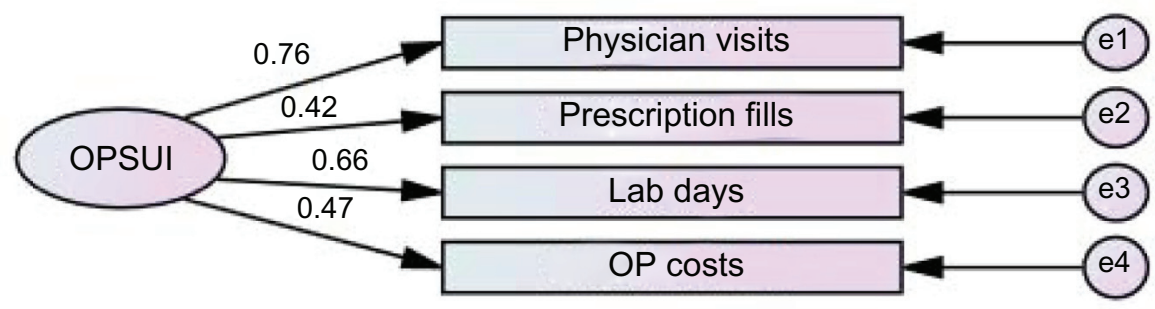

\section{Post-Year 1}

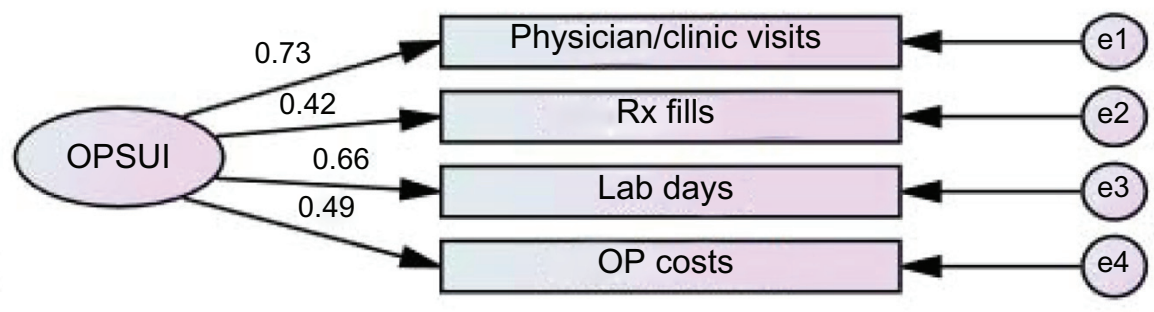

\section{Post-Year 2}

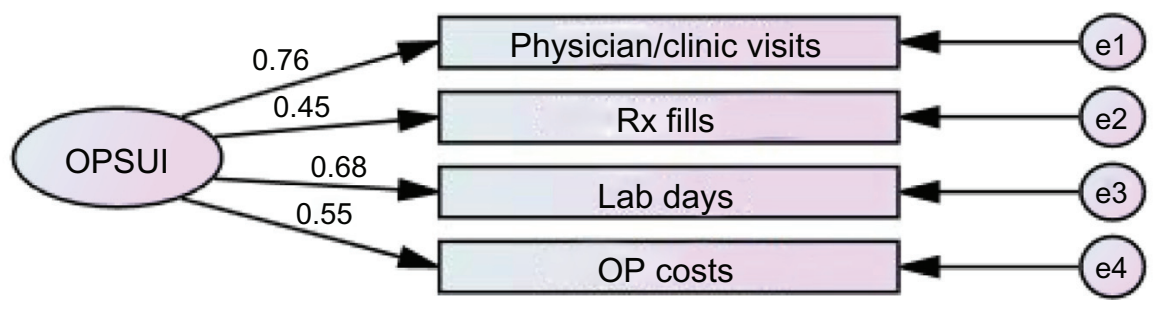

Figure 2 Factor analysis results: outpatient service utilization intensity (OPSUI).

Abbreviations: OP, outpatient; OPSUI, outpatient service utilization intensity; Rx, prescription.

Compared with the Low to Low group, members in the High to High group displayed a nonsignificant positive trend toward being slightly younger $(\beta=-0.013, P<0.05)$ and male $(\beta=0.209, \operatorname{Exp}(\beta)=1.232, P<0.05)$. Further, they utilized greater baseline high-cost venue services ( $\beta=0.263, P<0.001)$, greater post-Year 1 outpatient services $(\beta=0.716, P<0.001)$, and filled a greater number of prescriptions for different opioids $(\beta=0.219, P<0.001)$. The High to High group tended to have elevated Charlson comorbidity index scores $(\beta=0.275, P<0.001)$ and were more likely to be diagnosed with the following specific comorbidities during the pre-period: opioid dependence $(\beta=0.865, \operatorname{Exp}(\beta)=2.375, P<0.001)$, cardiovascular disease $(\beta=0.317, \operatorname{Exp}(\beta)=1.373, P<0.01)$, and migraine $(\beta=0.851, \operatorname{Exp}(\beta)=2.343, P<0.001)$. In addition, there was a nonsignificant positive trend for fibromyalgia $(\beta=0.381$, $\operatorname{Exp}(\beta)=1.464, P<0.05)$.

Compared with the Low to Low group, members in the Low to High group were significantly older $(\beta=0.014$, $P<0.001)$, utilized greater pre-period high-cost venue services $(\beta=0.185, P<0.001)$, utilized greater post-Year 1 outpatient services $(\beta=0.400, P<0.001)$, and filled a greater number of prescriptions for different opioids $(\beta=0.109$, $P<0.001)$. In addition, there was a nonsignificant positive trend toward males $(\beta=0.118, \operatorname{Exp}(\beta)=1.126, P<0.05)$. The Low to High group tended to have elevated Charlson comorbidity index scores $(\beta=0.171, P<0.001)$ and were more likely to be diagnosed with the following specific 
Table 3 Study sample descriptive statistics by trajectory group (based on pre-period information)

\begin{tabular}{|c|c|c|c|c|c|c|c|c|}
\hline \multirow[t]{2}{*}{ Variable } & \multicolumn{2}{|c|}{$\begin{array}{l}\text { High to high } \\
(N=469)\end{array}$} & \multicolumn{2}{|c|}{$\begin{array}{l}\text { Low to high } \\
(N=1612)\end{array}$} & \multicolumn{2}{|c|}{$\begin{array}{l}\text { Low to low } \\
(N=66,758)\end{array}$} & \multicolumn{2}{|c|}{$\begin{array}{l}\text { High to low } \\
(N=2553)\end{array}$} \\
\hline & Mean/f & $(\mathbf{S D}) / \%$ & Mean/f & $(\mathbf{S D}) / \%$ & Mean/f & (SD)/\% & Mean/f & (SD) $/ \%$ \\
\hline Low back pain & 237 & $50.50 \%$ & 807 & $50.10 \%$ & 35675 & $53.40 \%$ & 1272 & $49.80 \%$ \\
\hline Osteoarthritis & 232 & $49.50 \%$ & 805 & $49.90 \%$ & 31083 & $46.60 \%$ & $|28|$ & $50.20 \%$ \\
\hline Male & 167 & $35.60 \%$ & 626 & $40.10 \%$ & 26776 & $40.10 \%$ & 1040 & $40.70 \%$ \\
\hline Age & 47.6 & 9.7 & 49.7 & 8.6 & 47.5 & 9.3 & 50.1 & 8.8 \\
\hline Northeast region & 22 & $4.70 \%$ & 92 & $5.70 \%$ & 4547 & $6.80 \%$ & 160 & $6.30 \%$ \\
\hline North central region & 122 & $26.00 \%$ & 434 & $26.90 \%$ & 19,654 & $29.40 \%$ & 680 & $26.60 \%$ \\
\hline South region & 272 & $58.00 \%$ & 855 & $53.00 \%$ & 32,960 & $49.40 \%$ & 1346 & $52.70 \%$ \\
\hline West region & 50 & $10.70 \%$ & 223 & $13.80 \%$ & 9340 & $14.00 \%$ & 359 & $14.10 \%$ \\
\hline Unknown region & 3 & $0.60 \%$ & 8 & $0.50 \%$ & 257 & $0.40 \%$ & 8 & $0.30 \%$ \\
\hline Charlson comorbidity index & 0.77 & $\mathrm{I} .08$ & 0.43 & 0.81 & 0.2 & 0.52 & 0.43 & 0.8 \\
\hline \multicolumn{9}{|l|}{ Related comorbidities and covariates } \\
\hline Depression & 48 & $10.20 \%$ & 92 & $5.70 \%$ & 1870 & $2.80 \%$ & 105 & $4.10 \%$ \\
\hline Anxiety & 27 & $5.80 \%$ & 64 & $4.00 \%$ & 1789 & $2.70 \%$ & 91 & $3.60 \%$ \\
\hline Opioid dependence & 23 & $4.90 \%$ & 38 & $2.40 \%$ & 654 & $1.00 \%$ & 54 & $2.10 \%$ \\
\hline Bipolar disorder & 10 & $2.10 \%$ & 24 & $1.50 \%$ & 318 & $0.50 \%$ & 21 & $0.80 \%$ \\
\hline Sleep disturbance/insomnia & 40 & $8.50 \%$ & 136 & $8.40 \%$ & 3056 & $4.60 \%$ & 197 & $7.70 \%$ \\
\hline Sickle cell disease & 8 & $1.70 \%$ & 2 & $0.10 \%$ & 4 & $0.00 \%$ & 0 & $0.00 \%$ \\
\hline Fibromyalgia & 42 & $9.00 \%$ & 71 & $4.40 \%$ & 2130 & $3.20 \%$ & 107 & $4.20 \%$ \\
\hline Cardiovascular disease & 192 & $40.90 \%$ & 582 & $36.10 \%$ & 14,354 & $21.50 \%$ & 879 & $34.40 \%$ \\
\hline Migraine/chronic headache & 60 & $12.80 \%$ & 68 & $4.20 \%$ & 1593 & $2.40 \%$ & III & $4.30 \%$ \\
\hline Post-traumatic stress disorder & 4 & $0.90 \%$ & 5 & $0.30 \%$ & 146 & $0.20 \%$ & 8 & $0.30 \%$ \\
\hline Mental health visits $(\mathrm{N})$ & 83 & $17.70 \%$ & 177 & $11.00 \%$ & 4417 & $6.60 \%$ & 227 & $8.90 \%$ \\
\hline Psychotropic Rx fills (N) & 216 & $46.10 \%$ & 531 & $32.90 \%$ & 14,437 & $21.60 \%$ & 765 & $30.00 \%$ \\
\hline HCVSUI factor score & 2.18 & 4.85 & 0.4 & 1.97 & -0.04 & 0.79 & 0.45 & 1.93 \\
\hline OPSUI factor score & 1.5 & 2.2 & 0.5 & 1.35 & -0.04 & 0.93 & 0.5 & 1.58 \\
\hline
\end{tabular}

Abbreviations: HCVSUI, high-cost venue service utilization intensity; OPSUl, outpatient service utilization intensity; Rx, prescription; SD, standard deviation.

comorbidities during the pre-period: opioid dependence $(\beta=0.563, \operatorname{Exp}(\beta)=1.755, P<0.01)$, cardiovascular disease $(\beta=0.321, \operatorname{Exp}(\beta)=1.379, P<0.001)$, and bipolar disorder $(\beta=0.665, \operatorname{Exp}(\beta)=1.944, P<0.01)$. In addition, there was a nonsignificant positive trend for depression $(\beta=0.227, \operatorname{Exp}(\beta)=1.255, P<0.05)$.

Compared with the Low to Low group, members in the High to Low group were significantly older ( $\beta=0.020, P<0.001)$, more likely to be male $(\beta=0.260$, $\operatorname{Exp}(\beta)=1.297, P<0.01)$, utilized greater baseline highcost venue services $(\beta=0.179, P<0.001)$, utilized greater post-Year 1 outpatient services $(\beta=0.645, P<0.001)$, and filled a greater number of prescriptions for different opioids ( $\beta=0.102, P<0.001)$. The High to Low group did not have elevated Charlson comorbidity index scores $(P>0.05)$; however, they were more likely to be diagnosed with opioid dependence $(\beta=0.493$, $\operatorname{Exp}(\beta)=1.637, P<0.01)$. In addition, there were nonsignificant positive trends for cardiovascular disease $(\beta=0.113, \operatorname{Exp}(\beta)=1.119, P<0.05)$ during the pre-period and members were less likely to be diagnosed with depression $(\beta=-0.256$, Exp $(\beta)=0.774$, $P<0.05)$.

\section{Discussion}

The goals of the long-term pharmaceutical management of CNCP are largely palliative and rely on one or a combination of opioid therapy, neurological medications, and/or antidepressants. As has been adequately documented elsewhere, it is a challenge for practitioners to manage their CNCP patients regardless of the implemented treatment strategy. ${ }^{18,19}$ Finding the right balance between pain relief and appropriate medication combinations and levels is particularly challenging when addressing opioid therapy. There is a dearth of literature on the use of long-term opioid therapy for CNCP, although Chou and colleagues ${ }^{20}$ have published guidelines and the World Health Organization's analgesic ladder provides some guidance as well. ${ }^{9}$ Most agree that maximization of the patient's level of functioning is of paramount importance. However, health plans would argue that, in addition, efficiency or reduction in unnecessary use of high-cost venue services is equally important. This study highlights patient markers that might be used to meet both of these goals.

First, if service utilization can be taken as a proxy of patient level of functioning, an increased utilization of hospital-based services would indicate poor overall outcomes 


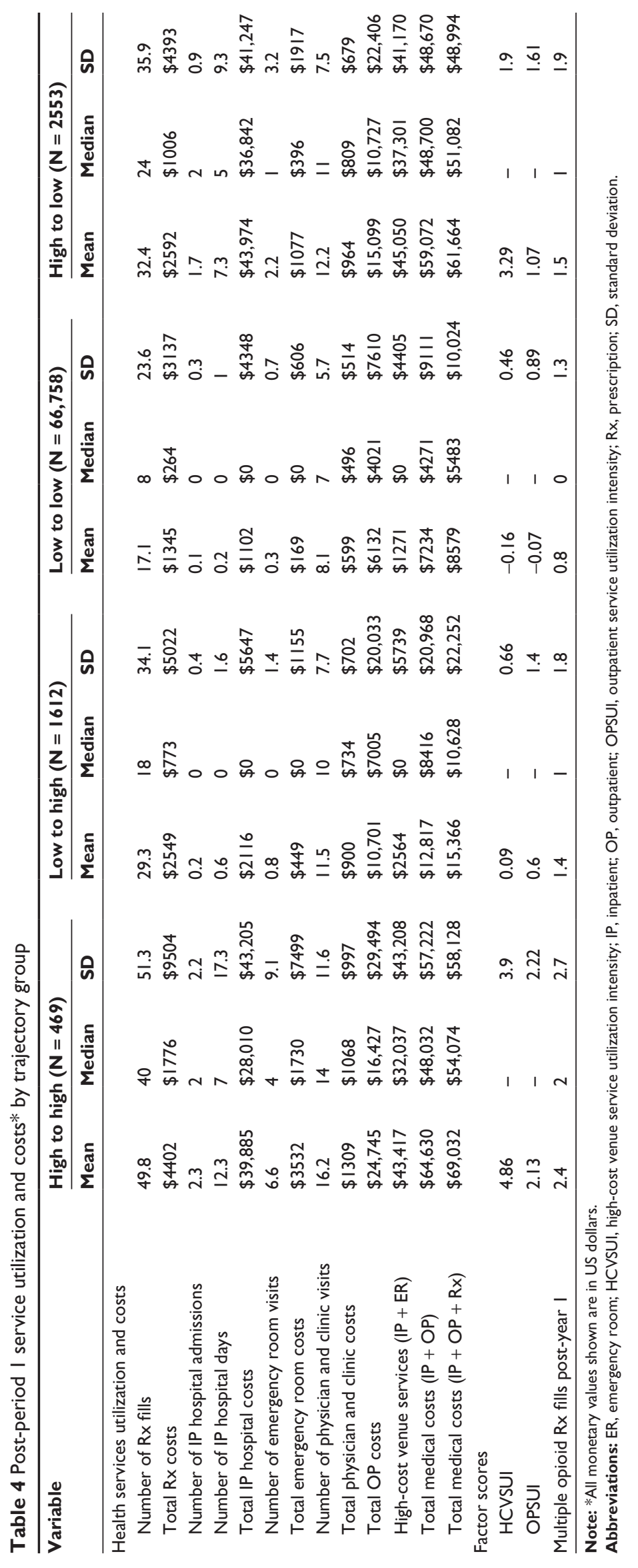




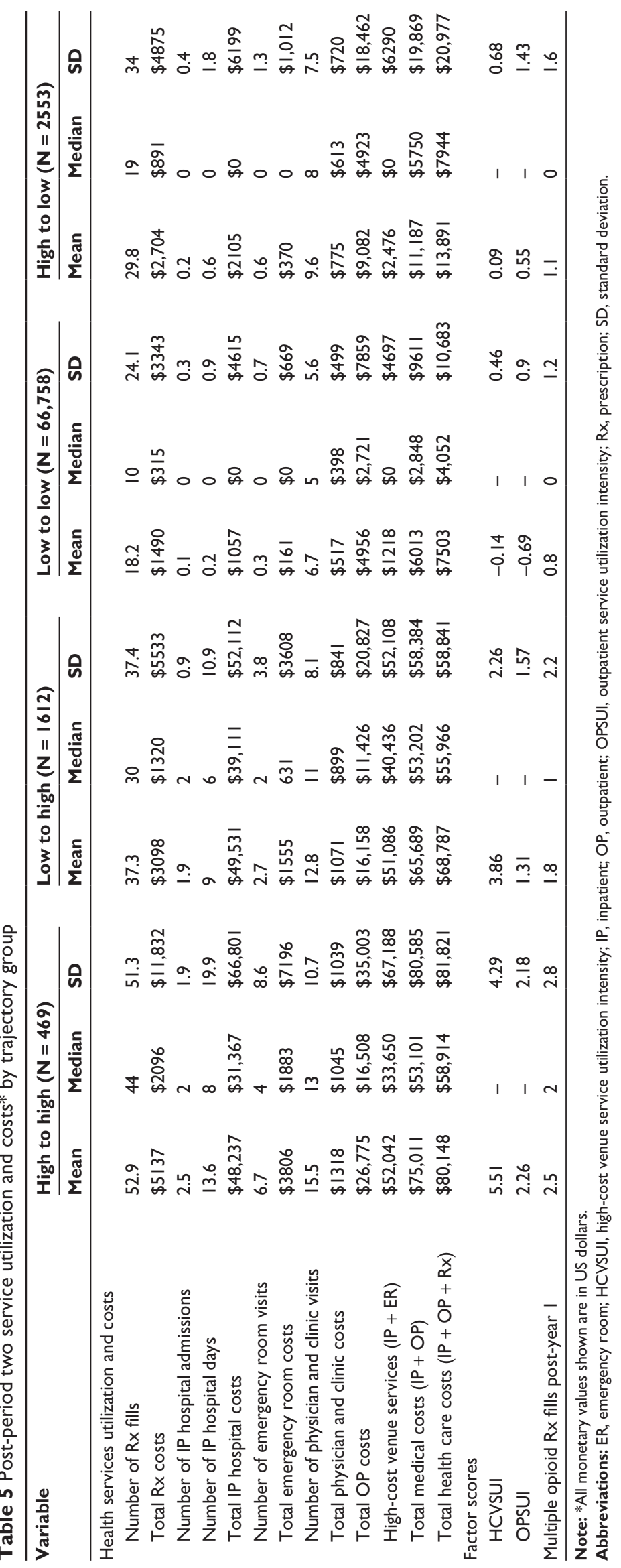




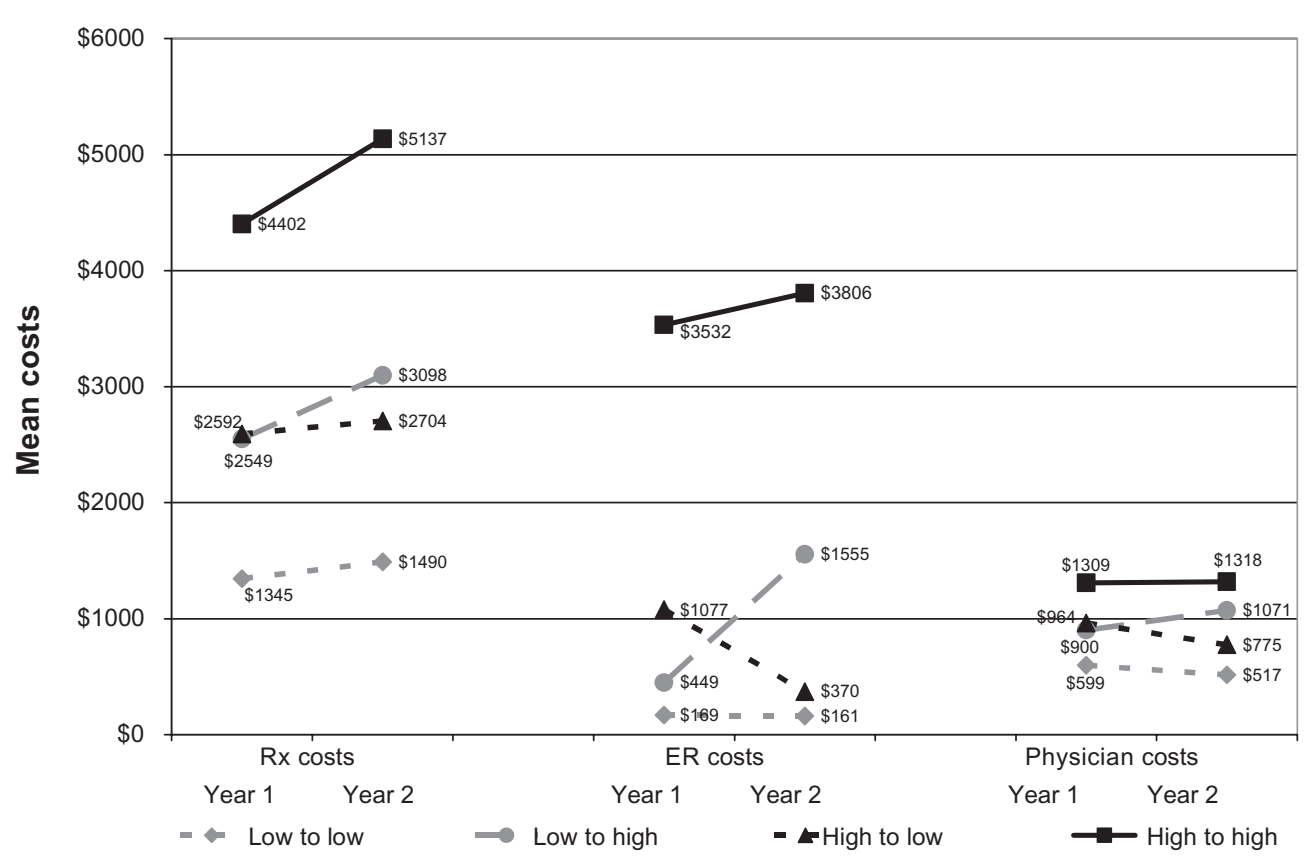

Figure 3 Mean service utilization costs (in US dollars).

Abbreviations: ER, emergency room; Rx, prescription.

to which suboptimal pain management may be a contributor. In the present study, predictors of post-Year 1 and post-Year 2 high-cost venue service utilization included history of highcost service utilization, the Charlson comorbidity index score, history of opioid dependence, and cardiovascular disease. Specifically, among those that remained consistently among the highest utilizers of high-cost venue services, migraine headache and a directionally correct trend $(P<0.05)$ for fibromyalgia were significant predictors. Furthermore, those in the Low to High group were more likely to have a history of mood disorder - specifically, bipolar - and a directionally correct trend $(P<0.05)$ for depression. In addition, both the count of different opioid medications filled during the first year of treatment as well as the history of intensity of outpatient service utilization were positively associated with high utilization of high-cost venue services.

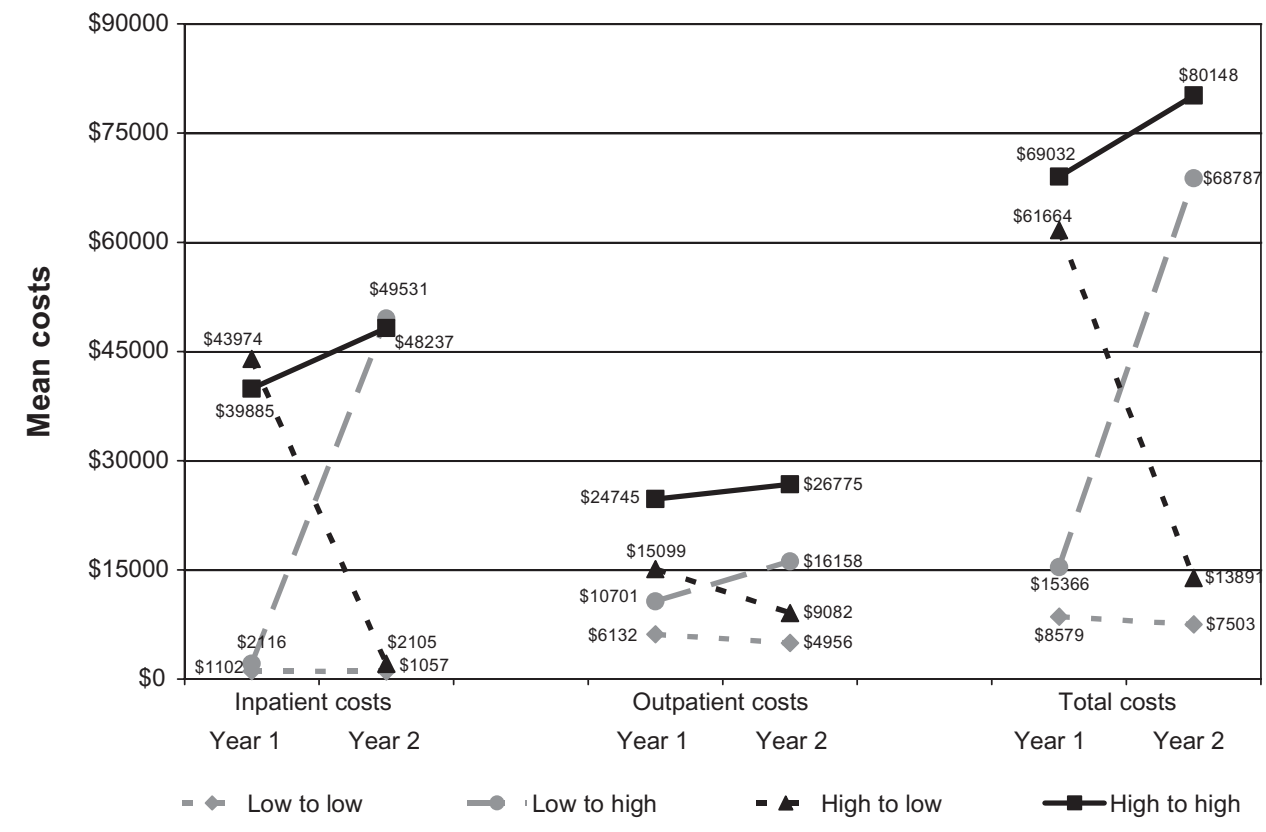

Figure 4 Mean total costs (in US dollars). 
Table 6 Final multinomial model of hospital-based service use by trajectory group ${ }^{\mathrm{a}}$

\begin{tabular}{|c|c|c|c|c|}
\hline & B & df & Significance & $\operatorname{Exp}(\beta)$ \\
\hline \multicolumn{5}{|l|}{ High to high } \\
\hline Intercept & -5.485 & I & 0.000 & \\
\hline Age & -0.013 & I & 0.019 & 0.987 \\
\hline Pre-period HCVSUI & 0.263 & I & 0.000 & 1.301 \\
\hline Post-period I OPSUI & 0.716 & I & 0.000 & 2.047 \\
\hline Charlson comorbidity & 0.275 & I & 0.000 & 1.317 \\
\hline Number of different opioids filled at post-period I & 0.219 & I & 0.000 & 1.245 \\
\hline Low back pain group & -0.194 & I & 0.052 & 0.824 \\
\hline Osteoarthritis group & $0^{\mathrm{b}}$ & 0 & & \\
\hline Male & 0.209 & I & 0.046 & 1.232 \\
\hline Depression diagnosis & 0.324 & I & 0.059 & 1.383 \\
\hline Opioid dependence diagnosis & 0.865 & I & 0.000 & 2.375 \\
\hline Bipolar diagnosis & 0.510 & I & 0.158 & 1.664 \\
\hline Fibromyalgia diagnosis & 0.381 & I & 0.035 & 1.464 \\
\hline Cardiovascular disease diagnosis & 0.317 & I & 0.003 & 1.373 \\
\hline Migraine diagnosis & $0.85 \mathrm{I}$ & I & 0.000 & 2.343 \\
\hline \multicolumn{5}{|l|}{ Low to high } \\
\hline Intercept & 4.848 & I & 0.000 & \\
\hline Age & 0.014 & I & 0.000 & 1.014 \\
\hline Pre-period HCVSUI & 0.185 & I & 0.000 & 1.203 \\
\hline Post-period I OPSUI & 0.400 & I & 0.000 & 1.492 \\
\hline Charlson comorbidity & 0.171 & I & 0.000 & 1.186 \\
\hline Number of different opioids filled at post-period I & 0.109 & I & 0.000 & 1.116 \\
\hline Low back pain group & -0.031 & I & 0.555 & 0.970 \\
\hline Osteoarthritis group & $0^{\mathrm{b}}$ & 0 & & \\
\hline Male & 0.118 & I & 0.026 & 1.126 \\
\hline Depression diagnosis & 0.227 & I & 0.048 & 1.255 \\
\hline Opioid dependence diagnosis & 0.563 & I & 0.001 & 1.755 \\
\hline Bipolar diagnosis & 0.665 & I & 0.003 & 1.944 \\
\hline Fibromyalgia diagnosis & 0.014 & I & 0.912 & 1.014 \\
\hline Cardiovascular disease diagnosis & 0.321 & I & 0.000 & 1.379 \\
\hline Migraine diagnosis & 0.219 & I & 0.095 & 1.245 \\
\hline \multicolumn{5}{|l|}{ High to low } \\
\hline Intercept & -4.752 & I & 0.000 & \\
\hline Age & 0.02 & I & 0.000 & 1.020 \\
\hline Pre-period HCVSUI & 0.179 & I & 0.000 & 1.196 \\
\hline Post-period I OPSUI & 0.645 & I & 0.000 & 1.906 \\
\hline Charlson comorbidity & 0.042 & 1 & 0.171 & 1.043 \\
\hline Number of different opioids filled at post-period I & 0.102 & I & 0.000 & 1.108 \\
\hline Low back pain group & -0.033 & I & 0.441 & 0.968 \\
\hline Osteoarthritis group & $0^{\mathrm{b}}$ & 0 & & \\
\hline Male & 0.260 & I & 0.000 & 1.297 \\
\hline Depression diagnosis & -0.256 & I & 0.020 & 0.774 \\
\hline Opioid dependence diagnosis & 0.493 & I & 0.001 & 1.637 \\
\hline Bipolar diagnosis & 0.028 & I & 0.908 & 1.028 \\
\hline Fibromyalgia diagnosis & -0.141 & I & 0.188 & 0.869 \\
\hline Cardiovascular disease diagnosis & 0.113 & I & 0.018 & 1.119 \\
\hline Migraine diagnosis & -4.752 & I & 0.122 & 1.181 \\
\hline
\end{tabular}

Notes: ${ }^{a}$ The reference category is: Low to Low; ${ }^{\text {this }}$ parameter is set to zero because it is redundant.

Abbreviations: B, beta; $\operatorname{Exp}(B)$, exponential beta; df, degrees of freedom; HSUI, ; OPSUl, outpatient service utilization intensity.

The presence of some of these clinical predictors of problematic opioid use and abuse is well documented within the CNCP population ${ }^{21,22}$ and opioid use has been related to both poor overall functioning ${ }^{23}$ and increased health care costs. ${ }^{12,22}$ The current study revealed the presence of a trend for depression and bipolar disorder associated with the Low to High group and depression was inversely associated with the High to Low group. Additionally, both opioid dependence as well as the number of different types of opioid prescriptions filled were positively predictive of 
high-cost service utilization. Finally, the overall prevalence of cardiovascular disease in the current sample $(22.4 \%)$ was below US prevalence estimates $(33 \%),{ }^{24}$ although it did vary significantly across trajectory groups, suggesting its importance in driving costs and as a covariate. However, when removed from the final model, the $\mathrm{R}^{2}$ was reduced by only 0.001 , indicating that it accounted for a small amount of the variance, so may not be as important as other predictors in the model.

One significant predictor in the opposite direction from previous literature and health plan policy is the positive relationship between high-cost venue service utilization and postYear 1 outpatient service utilization. Though not conclusive, these results do not support the general approach within care management, disease management, and case management programs of coordinating care using lower levels of service (ie, outpatient) to mitigate current or eventual elevated use of high-cost service among the CNCP patient population. ${ }^{25-28}$ Further, were this finding confirmed with more definitive data, it would suggest that health plans should reevaluate the effectiveness of standard chronic disease management protocols within this population. Clearly, health plan care management programs should look further into the effectiveness of these programs before assuming that they apply equally to CNCP patients.

An obvious application of an algorithm designed to predict high-cost service utilization based on the present results could be implemented within a health plan's care management process. Health plans may wish to intervene with patients at the greatest risk for utilization of avoidable high-cost venue services. These study results, though not definitive, indicate that there are readily available patient level predictors of high-cost service utilization among CNCP patients. Similarly, providers who are aware of the risk factors associated with high-cost service utilization may be better able to intervene in cases before health care expenditure begins to escalate. The successful identification of patients who are not at elevated risk of high-cost service utilization may be just as valuable. As the present study has shown, it is only a small portion of the entire CNCP population that will likely utilize the most expensive services, so implementation of such a program could be reasonably managed from a cost perspective. Finally, utilization reviewers and case managers within health plans, who often serve as the gatekeepers between individual patients and higher levels of care, may also increase patient care management effectiveness with the information gained from these results.
The primary limitation of the present study was the data source. Although claims data provide large sample sizes of bona fide transactions and services rendered in the health care arena, they do present a number of shortcomings. For one, the data included in this study came from an employer-based claims database that represents multiple health insurance plans and products. The variety of pain management policies are unknown and could not have been controlled. In addition, there is a dearth of clinical information in claims data, which otherwise could have assisted in both the categorization of patients into more meaningful groups and greater accuracy in assessing disease progression and treatment failure/response. Moreover, it should be understood that claims are submitted for reimbursement purposes, not research purposes; therefore, many assumptions about data definitions and, in some cases, how to interpret the results must be made to systematically measure the variables of interest and test research hypotheses. One final limitation, the inclusion of diagnosed opioid abuse/ dependence as a predictor in the model, while addressing the effect of opioid use and abuse directly, may have restricted the model, as users/abusers of drugs are more likely to try a greater number and fill more opioid prescriptions. ${ }^{29}$ Therefore, including participants in this model who were diagnosed with abuse/dependence of any drug, may lead to a more comprehensive model.

In closing, this study developed an algorithm to discriminate between patients based on use of high-cost venue health care services among CNCP patients. The ultimate goal was to identify patient characteristics that discriminated between different levels of HCVSUI and trajectories of change over time in the same. Overall, the current results improve our understanding of drivers of service utilization and costs among CNCP patients. Most notable among the results are the characteristic differences between trajectory groups and their clinical and care management implications. Characteristics related to $\mathrm{CNCP}$ patients across all three groups displayed elevated use of high-cost venue services, preperiod high-cost venue service utilization, post-Year 1 use of outpatient services, use of multiple different opioid medications during post-Year 1, and a history of opioid dependence. Primary diagnosis did not differentiate between the trajectory of high-cost venue service utilization. However, before we recommend that these groups be analyzed together, further analysis of these diagnoses and their effect on service utilization is necessary. By contrast, several other indicators did differentiate between groups and would be good candidates for use in case finding for health plans 
interested in programs to reduce the use of high-cost services among CNCP patients.

\section{Disclosure}

This study was funded by Janssen Scientific Affairs, LLC. At the time of study execution, authors Pai, Howe, and Bennett were employees of Janssen and receive salary, stock, and options. The other authors have no conflicts of interest to declare.

\section{References}

1. Classification of chronic pain. Descriptions of chronic pain syndromes and definitions of pain terms. Prepared by the International Association for the Study of Pain, Subcommittee on Taxonomy. Pain Suppl. 1986;3:S1-S226.

2. Gureje O, Von Korff M, Simon GE, Gater R. Persistent pain and wellbeing: a World Health Organization Study in Primary Care. JAMA. 1998;280(2):147-151.

3. Reid MC, Engles-Horton LL, Weber MB, Kerns RD, Rogers EL, O'Connor PG. Use of opioid medications for chronic noncancer pain syndromes in primary care. J Gen Intern Med. 2002;17(3):173-179.

4. Cicero TJ, Wong G, Tian Y, Lynskey M, Todorov A, Isenberg K. Co-morbidity and utilization of medical services by pain patients receiving opioid medications: data from an insurance claims database. Pain. 2009;144(1-2):20-27.

5. Fitzcharles MA, Ste-Marie PA, Gamsa A, Ware MA, Shir Y. Opioid use, misuse, and abuse in patients labeled as fibromyalgia. Am J Med. 2011;124(10):955-960.

6. American Chronic Pain Association. ACPA Resource Guide to Chronic Pain Medication and Treatment. Rocklin, CA: American Chronic Pain Association; 2012.

7. Gore M, Sadosky A, Stacey BR, Tai KS, Leslie D. The burden of chronic low back pain: clinical comorbidities, treatment patterns, and health care costs in usual care settings. Spine (Phila Pa 1976). 2012;37(11):E668-E677.

8. Martell BA, Oconnor PG, Kerns RD, Becker WC, Morales KH, Kosten TR, Fiellin DA. Systematic review: opioid treatment for chronic back pain: prevalence, efficacy, and association with addiction. Ann Intern Med. Jan 2007;146(2):116-127.

9. Vargas-Schaffer G. Is the WHO analgesic ladder still valid? Twenty-four years of experience. Can Fam Physician. 2010;56(6):514-517, e202-e515. French and English.

10. Automation of Reports and Consolidated Orders System (ARCOS). 2012; Available at: http://www.deadiversion.usdoj.gov/arcos/retail_ drug_summary/index.html. Accessed February 4, 2013.

11. Gore M, Sadosky A, Stacey BR, Tai KS, Leslie D. The burden of chronic low back pain: clinical comorbidities, treatment patterns, and health care costs in usual care settings. Spine (Phila Pa 1976). May 16, 2012;37(11):E668-E677.
12. Vogt MT, Kwoh CK, Cope DK, Osial TA, Culyba M, Starz TW. Analgesic usage for low back pain: impact on health care costs and service use. Spine (Phila Pa 1976). May 1, 2005;30(9):1075-1081.

13. Apkarian AV, Baliki MN, Geha PY. Towards a theory of chronic pain. Prog Neurobiol. Feb 2009;87(2):81-97.

14. Dunn KM, Jordan K, Croft PR. Characterizing the course of low back pain: a latent class analysis. Am J Epidemiol. Apr 15 2006;163(8): 754-761.

15. Ruetsch C. Empirical view of opioid dependence.J Manag Care Pharm. Feb 2010;16(1 Suppl B):S9-S13.

16. Gleicher Y, Croxford R, Hochman J, Hawker G. A prospective study of mental health care for comorbid depressed mood in older adults with painful osteoarthritis. BMC Psychiatry. 2011;11:147.

17. Labouvie $E$, Ruetsch, $C$. Testing for equivalence of measurement scales: simple structure and metric invariance reconsidered. Multivariate Behavioral Research. 1995;30(1):63-76.

18. Turk DC, Wilson HD, Cahana A. Treatment of chronic pain. Lancet. 2011;377:2226-2235.

19. Sarzi-Puttini P, Vellucci R, Zuccaro SM, Cherubino P, Labianca R, Fornasari D. The appropriate treatment for chronic pain. Clin Drug Investig. 2012;32(Suppl 1):21-33.

20. Chou R, Fanciullo GJ, Fine PG, et al. Clinical guidelines for the use of chronic opioid therapy in chronic noncancer pain. J Pain. Feb 2009;10(2):113-130.

21. Sehgal N, Manchikanti L, Smith HS. Prescription opioid abuse in chronic pain: a review of opioid abuse predictors and strategies to curb opioid abuse. Pain Physician. Jul 2012;15(3 Suppl):ES67-ES92.

22. Liebschutz JM, Saitz R, Weiss RD, et al. Clinical factors associated with prescription drug use disorder in urban primary care patients with chronic pain. J Pain. Nov 2010;11(11):1047-1055.

23. Manchikanti L, Fellows B, Ailinani H, Pampati V. Therapeutic use, abuse, and nonmedical use of opioids: a ten-year perspective. Pain Physician. Sep-Oct 2010;13(5):401-435.

24. Lloyd-Jones D, Adams R, Carnethon M, et al. Heart disease and stroke statistics-2009 update: a report from the American Heart Association Statistics Committee and Stroke Statistics Subcommittee. Circulation. Jan 27, 2009;119(3):e21-e181.

25. Lewis G, Wright L, Vaithianathan R. Multidisciplinary Case Management for Patients at High Risk of Hospitalization: Comparison of Virtual Ward Models in the United Kingdom, United States, and Canada. Popul Health Manag. Jul 12, 2012.

26. Fertig AR, Corso PS, Balasubramaniam D. Benefits and costs of a free community-based primary care clinic. J Health Hum Serv Adm. Spring 2012;34(4):456-470.

27. Coleman JR. Integrated case management: the 21 st century challenge for HMO case managers: Part I. Case Manager. Sep-Oct 1999;10(5): 28-34.

28. Dyck DG, Hendryx MS, Short RA, Voss WD, McFarlane WR. Service use among patients with schizophrenia in psychoeducational multiplefamily group treatment. Psychiatr Serv. Jun 2002;53(6):749-754.

29. Ives TJ, Chelminski PR, Hammett-Stabler CA, et al. Predictors of opioid misuse in patients with chronic pain: a prospective cohort study. $B M C$ Health Serv Res. 2006;6:46.
Journal of Pain Research

\section{Publish your work in this journal}

The Journal of Pain Research is an international, peer-reviewed, open access, online journal that welcomes laboratory and clinical findings in the fields of pain research and the prevention and management of pain. Original research, reviews, symposium reports, hypothesis formation and commentaries are all considered for publication.

\section{Dovepress}

The manuscript management system is completely online and includes a very quick and fair peer-review system, which is all easy to use. Visit http://www.dovepress.com/testimonials.php to read real quotes from published authors. 